\title{
Body Temperature Changes of Newborns Under Fluorescent Versus LED Phototherapy: Authors' Reply
}

\author{
Ozge Aydemir • Emel Soysaldı • Yusuf Kale • \\ Sumru Kavurt • Ahmet Yagmur Baș • Nihal Demirel
}

Received: 9 October 2013 / Accepted: 17 October 2013 / Published online: 6 November 2013

(C) Dr. K C Chaudhuri Foundation 2013

To the Editor: We read with great interest the comments of Aydin et al. on our recent article that compared the body temperature (BT) changes of newborns under conventional phototherapy with fluorescent lamps and light emitting diodes (LEDs) at different irradiances [1]. Intensive phototherapy is defined as irradiation of at least $30 \mu \mathrm{W} / \mathrm{cm}^{2} / \mathrm{nm}$ which can be easily achieved by LEDs [2]. However, an upper safety limit for intensive LED phototherapy has not been reported. The LED based phototherapy devices we have been using in our neonatal intensive care unit have 5 different levels of light intensity with a wide range of a spectral irradiance (30-120土 $\left.10 \mu \mathrm{W} / \mathrm{cm}^{2} / \mathrm{nm}\right)$. We had observed hyperthermia in a significant number of our patients who received LED phototherapy at level 3 and higher. Then, we planned a study to investigate changes in body temperature in term and late preterm infants during LED phototherapy at different irradiances.

For standardization purposes, in our study all infants were cared in double walled incubators during phototherapy and we did not include infants cared in open cribs. Thus, hypothermia was less likely. We observed that LED phototherapy of $\geq 60 \mu \mathrm{W} / \mathrm{cm}^{2} / \mathrm{nm}$ intensity significantly increased BT in hyperbilirubinemic newborns whereas LED phototherapy at low irradiances and conventional phototherapy with blue

O. Aydemir • E. Soysaldı • Y. Kale · S. Kavurt • A. Y. Baş •

N. Demirel

Department of Neonatology, Etlik Zübeyde Hanım Women's Health

Teaching and Research Hospital, Ankara, Turkey

O. Aydemir $(\bowtie)$

Neonatal Intensive Care Unit, Etlik Zübeyde Hanım Women's Health

Teaching and Research Hospital, Yeni Etlik Caddesi 55, Etlik,

06010 Ankara, Turkey

e-mail: drozgegenc@yahoo.com.tr fluorescent light did not cause significant hyperthermia. It was reported that LED based devices produce minimal heat while generating high irradiance [3]. We propose that increase in body temperature is a function of increase of irradiance and light energy heats the infants by radiation which is a method of heat transfer that does not rely upon contact between the heat source and the heated object. An alternative explanation for hyperthermia could be induction of pyrogenic cytokines by phototherapy [4].

In conclusion, closer monitoring of body temprature is needed for newborns under phototherapy at high irradiances.

Contributions OA: Planning of the study, interpretation of the data, statistical analysis and manuscript writing; ES: Planning of the study, collection of the data; YK: Collection of the data, interpretation of the data; SK: Collection of the data; AYB: Planning of the study; ND: Planning of the study, manuscript writing. ND will act as guarantor for this paper.

Conflict of Interest None.

Role of Funding Source None.

\section{References}

1. Aydemir O, Soysaldı E, Kale Y, Kavurt S, Bas AY, Demirel N. Body temperature changes of newborns under fluorescent versus LED phototherapy. Indian J Pediatr. 2013. doi:10.1007/s12098-013-1209-2.

2. American Academy of Pediatrics Subcommittee on Hyperbilirubinemia. Management of hyperbilirubinemia in the newborn infant 35 or more weeks of gestation. Pediatrics. 2004;114:297-316.

3. Maisels MJ. Phototherapy-Traditional and nontraditional. J Perinatol. 2001;21:93-7.

4. Kurt A, Aygun AD, Kurt AN, Godekmerdan A, Akarsu S, Yilmaz E. Use of phototherapy for neonatal hyperbilirubinemia affects cytokine production and lymphocyte subsets. Neonatology. 2009;95:262-6. 